\title{
Efficacy and safety of different doses and retreatment of rituximab: a randomised, placebo-controlled trial in patients who are biological naïve with active rheumatoid arthritis and an inadequate response to methotrexate (Study Evaluating Rituximab's Efficacy in MTX iNadequate rEsponders (SERENE))
}

\author{
P Emery, ${ }^{1}$ A Deodhar, ${ }^{2}$ W F Rigby, ${ }^{3} \mathrm{~J} \mathrm{D}$ Isaacs, ${ }^{4} \mathrm{~B}$ Combe, ${ }^{5} \mathrm{~A} \mathrm{~J}$ Racewicz, ${ }^{6} \mathrm{~K}$ Latinis, ${ }^{7}$ \\ C Abud-Mendoza, ${ }^{8}$ L J Szczepański, ${ }^{9}$ R A Roschmann, ${ }^{10}$ A Chen, ${ }^{11} \mathrm{G} \mathrm{K} \mathrm{Armstrong,},{ }^{12}$ \\ W Douglass, ${ }^{12} \mathrm{H}$ Tyrrell $^{12}$
}

- Additional data are published online only. To view these files please visit the journal online (http://ard.bmj.com)

${ }^{1}$ Section of Musculoskeletal Disease, Leeds University, Leeds, UK

${ }^{2}$ Oregon Health \& Science University, Portland, Oregon, USA ${ }^{3}$ Dartmouth Hitchcock Medical Center, Lebanon, New

Hampshire, USA

${ }^{4}$ Newcastle University, Newcastle upon Tyne, UK ${ }^{5}$ Lapeyronie Hospital,

Montpellier, France

${ }^{6}$ Department of Internal

Medicine and Osteoarthrology,

Bialystok Regional Hospital,

Bialystok, Poland

${ }^{7}$ Kansas University Medical Center, Kansas City, Kansas, USA

${ }^{8} \mathrm{Hospital}$ Central and Faculty of Medicine, University of San Luis Potosí, San Luis Potosí, México ${ }^{9}$ Wydz Fizjoterapii, WSSP im

W. Pola, Lublin, Poland

${ }^{10}$ Advanced Musculoskeletal Institute, Kalamazoo, Michigan, USA

${ }^{11}$ Genentech Inc, South San

Francisco, California, USA

${ }^{12}$ Roche Products, Welwyn

Garden City, UK

\section{Correspondence to}

Paul Emery, Section of

Musculoskeletal Disease, Leeds Institute of Molecular Medicine, University of Leeds, Chapel Allerton Hospital, Chapeltown Road, Leeds LS7 4SA, UK; p.emery@leeds.ac.uk

Accepted 31 January 2010

\section{UNLOCKED}

This paper is freely available online under the BMJ Journals unlocked scheme, see http:// ard.bmj.com/info/unlocked.dtl

\section{ABSTRACT}

Objectives This phase III study evaluated the efficacy and safety of rituximab plus methotrexate (MTX) in patients with active rheumatoid arthritis (RA) who had an inadequate response to MTX and who were naïve to prior biological treatment.

Methods Patients with active disease on stable MTX (10-25 mg/week) were randomised to rituximab $2 \times 500 \mathrm{mg}(\mathrm{n}=168)$, rituximab $2 \times 1000 \mathrm{mg}(\mathrm{n}=172)$, or placebo $(n=172)$. From week 24, patients not in remission (Disease Activity Score (28 joints) $\geq 2.6$ ) received a second course of rituximab; patients initially assigned to placebo switched to rituximab $2 \times 500 \mathrm{mg}$. The primary end point was American College of Rheumatology 20 (ACR20) response at week 24. All patients were followed until week 48 .

Results At week 24, both doses of rituximab showed statistically superior efficacy $(p<0.0001)$ to placebo (ACR20: 54\%, 51\% and 23\%; rituximab (2×500 mg) + MTX, rituximab $(2 \times 1000 \mathrm{mg})+$ MTX and placebo + MTX, respectively). Secondary end points were also significantly improved for both rituximab groups compared with placebo. Further improvements in both rituximab arms were observed from week 24 to week 48 . Rituximab + MTX was well tolerated, demonstrating comparable safety to placebo + MTX through to week 24, and between rituximab doses through to week 48 .

Conclusions Rituximab (at $2 \times 500 \mathrm{mg}$ and $2 \times 1000$ $\mathrm{mg}$ ) plus MTX significantly improved clinical outcomes at week 24 , which were further improved by week 48 . No significant differences in either clinical or safety outcomes were apparent between the rituximab doses.

\section{INTRODUCTION}

Rituximab, a monoclonal antibody against CD20 that selectively targets B cells, has demonstrated significant efficacy with good tolerability in clinical trials conducted in patients with active rheumatoid arthritis (RA). ${ }^{1}{ }^{2}$ Rituximab $2 \times 1000 \mathrm{mg}$ plus methotrexate (MTX) significantly improved clinical disease symptoms in patients with an intolerance or an inadequate response to tumour necrosis factor (TNF) inhibitors. ${ }^{2}$ In patients with an inadequate response to disease- modifying antirheumatic drugs (DMARDs), doses of $2 \times 500 \mathrm{mg}$ and $2 \times 1000 \mathrm{mg}$ of rituximab have shown clinical benefit. ${ }^{3}$ Limited information suggested that the $2 \times 1000 \mathrm{mg}$ dose was associated with higher levels of response.

This study further investigated the efficacy and safety of rituximab $2 \times 500 \mathrm{mg}$ and $2 \times 1000 \mathrm{mg}$ in combination with MTX, in patients with active RA who had an inadequate response to MTX and in whom no prior biological treatment for RA had been administered. Maintenance of response and long-term safety following retreatment with rituximab were explored.

\section{METHODS}

This was a multicentre, randomised, double-blind, placebo-controlled, phase III study conducted at 102 centres in 11 countries. Eligible patients were aged 18-80 years with RA according to American College of Rheumatology (ACR) criteria for $\geq 6$ months, which was active despite MTX (10-25 mg/week for at least 12 weeks). Active disease was defined as swollen joint count (SJC) and tender joint count (TJC) both $\geq 8$, and either C reactive protein $(\mathrm{CRP}) \geq 0.6 \mathrm{mg} / \mathrm{dl}$ or erythrocyte sedimentation rate $(E S R) \geq 28 \mathrm{~mm} / \mathrm{h}$. Patients also had to have an absolute neutrophil count $\geq 1500$ cells/ $\mu 1$, a haemoglobin level $\geq 8 \mathrm{~g} / \mathrm{dl}$ and IgM and IgG levels of $\geq 40$ and $\geq 500 \mathrm{mg} / \mathrm{dl}$, respectively. Patients had not previously received biological treatment for RA.

The study was performed in accordance with the Declaration of Helsinki. All participating sites received approval from their governing institutional review board (or equivalent) and all patients provided written informed consent.

\section{Treatments}

All patients underwent at least a 2 -week washout for all DMARDs (leflunomide $\geq 8$ weeks or $\geq 14$ days after cholestyramine or activated charcoal washout), but continued to receive concomitant MTX (10-25 mg/week) at a stable dose together with folic acid $\geq 5 \mathrm{mg} /$ week or equivalent. Stable dose oral corticosteroids $(\leq 10 \mathrm{mg} /$ day 
prednisolone or equivalent) and non-steroidal anti-inflammatory drugs were permitted.

Patients were randomised (1:1:1) to one of three treatment groups: rituximab $2 \times 500 \mathrm{mg}$, rituximab $2 \times 1000 \mathrm{mg}$, or placebo administered by intravenous infusion on days 1 and 15 . All infusions (including placebo) were premedicated with intravenous methylprednisolone $100 \mathrm{mg}$.

Between week 16 and week 23 , patients with $<20 \%$ improvement in TJC and SJC versus baseline were allowed rescue treatment with one non-biological DMARD, which was continued for the remainder of the study.

Repeat courses of open-label rituximab were scheduled from week 24. Eligible patients were those not in remission, (Disease Activity Score (DAS28-ESR) $\geq 2.6$ ), who also met predefined safety criteria (neutrophil count $>1500$ cells/ $/$ l). Patients were retreated with their randomised dose of rituximab or, if initially assigned to placebo, switched to receive rituximab (2×500 mg).

\section{Assessments}

Clinical efficacy assessments including ACR core set, ${ }^{4}$ were assessed at baseline and at either 4-week or 8-week intervals to week 48. The Functional Assessment of Chronic Illness Therapy-Fatigue (FACIT-F) was assessed at baseline and weeks 12, 24 and 48; the Medical Outcomes Study 36-item Short Form Health Survey (SF-36) was assessed at baseline, week 24 and week 48.

Laboratory assessments included peripheral B cells, Igs and human anti-chimaeric antibodies (HACA) to rituximab.

Adverse events (AEs) and serious AEs were recorded throughout the study and rates were calculated. Rates of infections and serious infections per 100 patient-years were calculated.

\section{Clinical outcome measures}

The primary end point was the proportion of patients with an ACR20 response at week 24 . Secondary end points at week 24 included proportions of patients achieving ACR50/70, European League Against Rheumatism (EULAR) responses, DAS28-ESR (mean change, low disease activity (LDA $\leq 3.2$ ) and remission $(<2.6)$ ), Health Assessment Questionnaire Disability Index (HAQ-DI) (mean change, proportion of patients achieving a minimal clinically important difference (MCID; improvement of $\geq 0.22)$ ), ${ }^{5}$ SF-36 (mean change summary scores, proportion of patients achieving the mental and physical component score MCIDs (6.33 and 5.42, respectively) $)^{6}$ and FACIT-F assessment. ${ }^{8}$ Comparisons were made between the rituximab + MTX groups versus placebo + MTX.

At week 48 the proportions of patients achieving ACR50 and ACR70 responses, DAS28-ESR LDA and remission, and EULAR responses were compared between rituximab dose groups.

\section{Sample size estimation}

A target sample size of 167 patients per arm was estimated to provide at least $90 \%$ power to detect differences in the proportions of patients with an ACR20 response at week 24 between each rituximab group versus placebo + MTX, using Fisher's exact test, adjusting for multiplicity with a two-sided significance level of $p<0.025$ for each test.

\section{Statistical analysis}

The efficacy of rituximab versus placebo was analysed using the Cochran-Mantel-Haenszel test for categorical end points and analysis of variance (ANOVA) for continuous end points, adjusting for baseline stratification factors of rheumatoid factor (RF) status and region (USA vs non-USA). ANOVA models also included the end point's baseline value, if applicable.

Missing data, including data for patients who withdrew or received rescue treatment, were imputed using the non-responder method for ACR and EULAR and last observation carried forward (LOCF) for all other end points.

The intention-to-treat (ITT) and safety populations were defined as all patients who were randomised and received any part of an infusion of study medication.

\section{RESULTS}

A total of 511 patients were randomised; 509 received at least 1 infusion (ITT population). Over $90 \%$ of patients completed 48 weeks of the study (table 1).

Demographic and baseline disease characteristics were well balanced across the three groups (table 2). Patients had a mean disease duration of approximately 7 years, with high disease activity (mean DAS28-ESR 6.40-6.54).

\section{Clinical outcomes}

\section{Week 24 (placebo-controlled period)}

Atweek 24 , a significantly greater proportion of patients receiving rituximab $2 \times 500 \mathrm{mg}$ or $2 \times 1000 \mathrm{mg}+$ MTX achieved an ACR20 response versus patients receiving placebo + MTX $(54.5 \%$ and $50.6 \%$ vs $23.3 \%$, respectively; $p<0.0001$ ) (figure 1 ). Significantly greater proportions of patients receiving rituximab $2 \times 500 \mathrm{mg}$ or $2 \times 1000 \mathrm{mg}+$ MTX also achieved ACR50 versus those receiving placebo + MTX $(26.3 \%$ and $25.9 \%$ vs $9.3 \%$, respectively; $\mathrm{p}<0.0001$ ) (figure 1). ACR70 responses were achieved by a greater proportion of patients receiving either dose of rituximab + MTX versus those receiving placebo + MTX, although the differences did not achieve statistical significance (figure 1).

For both rituximab + MTX dose groups there were significantly greater mean decreases in all individual components of the ACR core set $(p \leq 0.0007)$, and significantly greater mean changes in DAS28-ESR $(p<0.0001)$ versus the placebo + MTX group. Significantly higher proportions of patients receiving rituximab + MTX achieved EULAR responses, LDA and remission than placebo + MTX patients $(\mathrm{p}<0.05)($ table 3$)$.

Both rituximab doses produced statistically significant improvements in patient-reported outcomes as demonstrated by changes in HAQ-DI, FACIT-F and SF-36 scores (table 3). Higher proportions of patients receiving rituximab + MTX also achieved MCIDs for HAQ and SF-36 subscales (table 3).

\section{Week 48 (including second course of rituximab)}

By week 48 approximately $90 \%$ of patients in all treatment groups had received a second course of treatment. The majority of these repeat treatments ( $82 \%$ to $88 \%$ ) were given by week 30.

Mean DAS28-ESR scores over the 48-week period for all treatment arms are presented in figure 2 and show maintained or improved levels of disease activity throughout the 48-week period with both doses of rituximab + MTX. Mean changes in DAS at week 48 were greater than at week 24 for both rituximab dose groups (table 3). At week 48, clinical responses (ACR and EULAR responses) were maintained in both rituximab groups versus week 24 , with the majority of end points showing some improvement (figure 1 and table 3). Comparisons between the rituximab doses at week 48 did not identify significant differences for any clinical end point. 
Table 1 Disposition of patients up to week 48

\begin{tabular}{|c|c|c|c|}
\hline Patients, n (\%) & Placebo + MTX & $\begin{array}{l}\text { Rituximab } 2 \times 500 \mathrm{mg} \\
+ \text { MTX }\end{array}$ & $\begin{array}{l}\text { Rituximab } 2 \times 1000 \mathrm{mg} \\
+ \text { MTX }\end{array}$ \\
\hline Randomised* & $172(100)$ & $168(100)$ & $172(100)$ \\
\hline Treated (first course) $†$ & $172(100)$ & $167(99.4)$ & $170(98.8)$ \\
\hline Completed 24 weeks (placebo-controlled period) & $159(92.4)$ & $162(96.4)$ & $166(96.5)$ \\
\hline Retreated (second course) & $154(89.5)$ & $152(90.5)$ & $154(89.5)$ \\
\hline Received rescue treatment post week 24 & $16(9.3 \%)$ & $6(3.6 \%)$ & $4(2.3 \%)$ \\
\hline Leflunomide (n) & 5 & 1 & 1 \\
\hline Hydroxychloroquine (n) & 4 & 2 & - \\
\hline Sulfasalazine (n) & 3 & 1 & 3 \\
\hline Cyclophosphamide (n) & 1 & - & - \\
\hline Ciclosporin (n) & 3 & 2 & - \\
\hline Completed 48 weeks (second course of rituximab) & $154(89.5)$ & $157(93.5)$ & $157(91.3)$ \\
\hline Withdrew before week 24 & $13(7.6)$ & $6(3.6)$ & $6(3.5)$ \\
\hline $\mathrm{AE} /$ intercurrent illness & $2(1.2)$ & $2(1.2)$ & $3(1.7)$ \\
\hline RA flare & $7(4.1)$ & $1(0.6)$ & 0 \\
\hline Failure to return & $1(0.6)$ & $1(0.6)$ & $3(1.7)$ \\
\hline Violation of selection criteria at entry & 0 & $1(0.6)$ & 0 \\
\hline Withdrew consent & $3(1.7)$ & 0 & 0 \\
\hline Administrative/other & 0 & $1(0.6)$ & 0 \\
\hline Withdrew before week 48 & $18(10.5)$ & $11(6.5)$ & $15(8.7)$ \\
\hline $\mathrm{AE} /$ intercurrent illness & $3(1.7)$ & $3(1.8)$ & $7(4.1)$ \\
\hline Death & 0 & $2(1.2)$ & 0 \\
\hline RA flare & $11(6.4)$ & $2(1.2)$ & 0 \\
\hline Failure to return & $1(0.6)$ & $2(1.2)$ & $4(2.3)$ \\
\hline Violation of selection criteria at entry & 0 & $1(0.6)$ & 0 \\
\hline Refused treatment/did not cooperate & 0 & 0 & $1(0.6)$ \\
\hline Withdrew consent & $3(1.7)$ & 0 & $1(0.6)$ \\
\hline Administrative/other & 0 & $1(0.6)$ & $2(1.2)$ \\
\hline
\end{tabular}

*Although 512 patients are listed, 1 patient was randomised twice. The actual number of randomised patients is 511.

tIntention-to-treat and safety populations.

$A E$, adverse event; MTX, methotrexate; RA, rheumatoid arthritis.

Table 2 Demographics and baseline disease characteristics

\begin{tabular}{|c|c|c|c|}
\hline Characteristic & Placebo + MTX (n=172) & $\begin{array}{l}\text { Rituximab } 2 \times 500 \mathrm{mg}+ \\
\text { MTX }(\mathrm{n}=167)\end{array}$ & $\begin{array}{l}\text { Rituximab } 2 \times 1000 \mathrm{mg}+ \\
\text { MTX }(\mathrm{n}=170)\end{array}$ \\
\hline Mean (SD) age, years & $52.16(12.390)$ & $51.91(12.926)$ & $51.30(12.644)$ \\
\hline Female, n (\%) & $147(85.5)$ & $133(79.6)$ & $138(81.2)$ \\
\hline Caucasian, n (\%) & $142(82.6)$ & $134(80.2)$ & $137(80.6)$ \\
\hline Mean (SD) disease duration, years & $7.48(7.642)$ & $7.10(6.969)$ & $6.61(7.294)$ \\
\hline Mean (SD) MTX dose, mg/week & $16.6(4.30)$ & $15.4(4.02)$ & $16.1(4.25)$ \\
\hline Mean (SD) number of previous DMARDs* & $1.1(1.10)$ & $1.2(1.25)$ & $1.1(1.11)$ \\
\hline Patients receiving oral steroids, n (\%) & $82(47.7)$ & $80(47.9)$ & $67(39.4)$ \\
\hline Mean (SD) OCS dose, mg/day & $6.3(2.68)$ & $5.8(2.52)$ & $6.1(2.58)$ \\
\hline RF positive, n (\%) & $129(75.0)$ & $126(75.4)$ & $125(73.5)$ \\
\hline Mean (SD) total RF, IU/ml & $264.1(492.03)$ & $307.2(774.94)$ & $288.1(539.5)$ \\
\hline Mean (SD) SJC (66 joints) & $20.9(11.26)$ & $18.6(9.62)$ & $19.5(10.32)$ \\
\hline Mean (SD) TJC (68 joints) & $30.2(15.94)$ & $27.1(14.10)$ & $28.7(14.98)$ \\
\hline Mean (SD) DAS28-ESR & $6.54(1.015)$ & $6.40(0.951)$ & $6.49(1.061)$ \\
\hline Mean (SD) DAS28-CRP & $5.95(0.972)$ & $5.81(0.912)$ & $5.86(0.967)$ \\
\hline
\end{tabular}

*Excludes MTX

CRP, C reactive protein; DAS28, Disease Activity Score (28 joints); DMARDs, disease-modifying antirheumatic drugs; ESR, erythrocyte sedimentation rate; MTX, methotrexate; OCS, oral corticosteroid; RF, rheumatoid factor; SJC, swollen joint count; TJC, tender joint count.

\section{Subgroup analyses}

At week 24, a consistent treatment effect for both rituximab groups versus placebo was observed for ACR, EULAR and DAS28-ESR responses in medically important subgroups, including baseline seropositivity (either RF or anti-cyclic citrullinated peptide (anti-CCP) antibody), duration of RA and baseline DAS28-ESR. However, in patients receiving rituximab, there were generally greater falls in DAS28-ESR over time in patients who were seropositive $(n=144)$ compared with patients who were seronegative $(n=24)$ (supplementary figure 1). At week 48, responses were generally higher in patients who were seropositive. Notably for high-hurdle end points, in patients receiving rituximab $2 \times 1000 \mathrm{mg}+$ MTX, ACR50 and ACR70 were 35\% and $15 \%$ for patients who were seropositive versus $21 \%$ and $0 \%$ for patients who were seronegative (data not shown).

\section{Immunological outcomes}

Receipt of rituximab was associated with characteristic depletion of peripheral CD19+ cells, which was comparable between both rituximab doses. 
Mean IgA, IgG and IgM levels declined from baseline in all three study groups. The decrease up to week 24 was comparable for both rituximab doses and was greater than the decrease seen in the placebo group. At week 24 the proportion of patients with IgA, IgG and IgM levels below the laboratory lower limit of normal (LLN) were $1.9 \%, 1.9 \%$ and $6.4 \%$, respectively, in the rituximab $2 \times 500 \mathrm{mg}$ group; $2.6 \%, 1.3 \%$ and $6.6 \%$, respectively, in the rituximab $2 \times 1000 \mathrm{mg}$ group; and $1.4 \%, 0 \%$ and $0 \%$, respectively, in the placebo group. Mean levels continued to decline following the second course of rituximab. In all

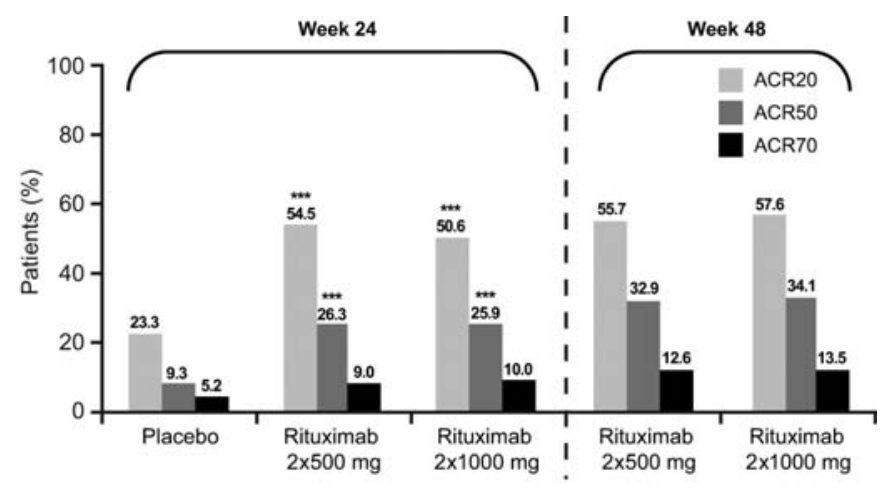

Figure 1 American College of Rheumatology (ACR) 20/50/70 responses at week 24 and week 48 in patients receiving placebo $(n=172)$, rituximab $2 \times 500 \mathrm{mg}(\mathrm{n}=167)$ or rituximab $2 \times 1000 \mathrm{mg}$ $(n=170)$ (all plus a stable dose of methotrexate $10-25 \mathrm{mg} /$ week), non-responder imputation (intention-to-treat population). ${ }^{* *} \mathrm{p} \leq 0.0001$ vs placebo. study groups, despite the above noted declines, mean IgA, IgG and IgM levels remained within normal limits throughout the study. The greatest change from baseline occurred in IgM, with an approximate $20 \%$ mean decrease from baseline at week 24 and $30 \%$ decrease by week 48 , in both rituximab dose groups, with minimal changes to IgG and IgA. No serious infections occurred in patients receiving rituximab while Ig levels were below the LLN.

At baseline, all patients were HACA negative. At week 24, positive HACA titres were observed in $7.9 \%, 5.4 \%$ and $3.6 \%$ of patients receiving rituximab $(2 \times 500 \mathrm{mg})+$ MTX, rituximab $(2 \times 1000 \mathrm{mg})+$ MTX and placebo + MTX, respectively. There was no apparent correlation between development of HACA and increased risk of infusion-related reactions (IRRs) or loss of response to subsequent retreatment with rituximab.

\section{Safety}

Safety to week 24 (placebo-controlled period)

During the 24-week placebo-controlled period, the overall incidence of AEs, serious AEs and AEs leading to withdrawal was similar across all treatment groups (table 4), with the most common AEs being IRRs, RA flares, nasopharyngitis and upper respiratory tract infections.

IRRs occurred more frequently with the first infusion of the first course in all three treatment groups, than with the second infusion of the same course (table 4). The incidence of IRRs was highest in patients receiving a first rituximab infusion of $1000 \mathrm{mg}$ $(25 \%)$ compared with a first infusion of $500 \mathrm{mg}$ rituximab or placebo (19\% and $14 \%$, respectively) (table 4). There were no serious IRRs reported during the initial treatment although one patient receiving rituximab $2 \times 1000 \mathrm{mg}$ withdrew due to an IRR

Table 3 Summary of disease-activity and quality-of-life clinical end points for patients treated with placebo vs rituximab $2 \times 500$ mg and $2 \times 1000 \mathrm{mg}$ (all plus a stable dose of methotrexate (MTX) 10-25 mg/week) at week 24 and week 48 (intention-to-treat population)

\begin{tabular}{|c|c|c|c|c|c|}
\hline \multirow[b]{2}{*}{ Clinical end point } & \multicolumn{3}{|l|}{ Week 24} & \multicolumn{2}{|l|}{ Week 48} \\
\hline & $\begin{array}{l}\text { Placebo }+ \\
\text { MTX }(n=172)\end{array}$ & $\begin{array}{l}\text { Rituximab } 2 \times 500 \mathrm{mg}+ \\
\operatorname{MTX}(\mathrm{n}=167)\end{array}$ & $\begin{array}{l}\text { Rituximab } 2 \times 1000 \mathrm{mg}+ \\
\operatorname{MTX}(\mathrm{n}=170)\end{array}$ & $\begin{array}{l}\text { Rituximab } 2 \times 500 \mathrm{mg}+ \\
\text { MTX }(\mathrm{n}=167)\end{array}$ & $\begin{array}{l}\text { Rituximab } \\
2 \times 1000 \mathrm{mg}+ \\
\text { MTX }(\mathrm{n}=170)\end{array}$ \\
\hline \multicolumn{5}{|l|}{ EULAR response, $\mathrm{n}(\%)$} & -2.02 \\
\hline Moderate & $50(29.1)$ & $82(49.1)^{* * *}$ & $87(51.2)^{* * *}$ & $89(53.3)$ & $81(47.6)$ \\
\hline Good & $8(4.7)$ & $29(17.4)^{* * *}$ & $20(11.8)^{* * *}$ & $33(19.8)$ & $35(20.6)$ \\
\hline \multicolumn{6}{|l|}{ DAS28-ESR end points, $\mathrm{n}(\%) \ddagger$} \\
\hline LDA (DAS28-ESR $\leq 3.2$ ) & $8(4.7)$ & $29(17.5)^{* *}$ & $21(12.4)^{*}$ & $33(20.0)$ & $41(24.3)$ \\
\hline Clinical remission (DAS28-ESR $<2.6$ ) & $4(2.3)$ & $16(9.6)^{* *}$ & $16(9.4)^{* *}$ & $15(9.1)$ & $19(11.2)$ \\
\hline $\begin{array}{l}\text { Clinically relevant HAQ-DI improvement, mean change from } \\
\text { baseline } \geq \text { MCID of } 0.22, n(\%) \S\end{array}$ & $82(47.7)$ & $109(66.1)^{* *}$ & $99(58.2)^{* *}$ & $121(73.3)$ & $117(68.8)$ \\
\hline \multicolumn{6}{|l|}{ FACIT-F change from baseline score $\mathbb{I}$} \\
\hline Adjusted mean & 2.12 & $5.51^{* *}$ & $6.53^{* * *}$ & NA & NA \\
\hline \multicolumn{6}{|l|}{ SF-36 mean change from baseline $\dagger \dagger$} \\
\hline \multicolumn{6}{|l|}{ SF-36 summary score mean adjusted } \\
\hline Mental component & 1.66 & 3.31 & $4.58^{* *}$ & NA & NA \\
\hline Physical component & 2.49 & $5.91^{* * *}$ & $5.70^{* * *}$ & NA & NA \\
\hline \multicolumn{6}{|l|}{ Clinically relevant improvement in summary score (n (\%)) } \\
\hline Mental health ( $\geq$ MCID of 6.33 ) & $35(23.8)$ & $51(33.6)$ & $54(34.8)^{*}$ & NA & NA \\
\hline Physical health ( $\geq$ MCID of 5.42 ) & $45(30.6)$ & $70(46.1)^{* *}$ & $75(48.4)^{* *}$ & NA & NA \\
\hline
\end{tabular}

Missing data were imputed using non-responder imputation for EULAR and ACR20/50/70 and LOCF for DAS28-ESR, LDA, clinical remission and quality-of-life end points.

${ }^{*} \mathrm{p}<0.05 ;{ }^{* *} \mathrm{p}<0.01 ;{ }^{* * *} \mathrm{p} \leq 0.0001$ vs placebo.

tNegative change represents an improvement. Patient numbers for this assessment: week 24 placebo $(n=171)$, rituximab $2 \times 500$ mg $(n=166)$, rituximab $2 \times 1000$ mg ( $n=168)$.

$\ddagger$ Patient numbers for this assessment: week 24 rituximab $2 \times 500 \mathrm{mg}+\operatorname{MTX}(\mathrm{n}=166)$; week 48 rituximab $2 \times 500 \mathrm{mg}+\mathrm{MTX}(\mathrm{n}=165)$, rituximab $2 \times 1000 \mathrm{mg}+\mathrm{MTX}(\mathrm{n}=169)$.

$\S$ Patient numbers for this assessment: weeks 24 and 48 rituximab $2 \times 500 \mathrm{mg}(\mathrm{n}=165)$.

IPatient numbers for this assessment: week 24 placebo $+\operatorname{MTX}(n=170)$, rituximab $2 \times 500 \mathrm{mg}(\mathrm{n}=165)$, rituximab $2 \times 1000 \mathrm{mg}(\mathrm{n}=168)$

t†Patient numbers for this assessment: week 24 placebo $+\operatorname{MTX}(n=147)$, rituximab $2 \times 500 \mathrm{mg}(\mathrm{n}=152)$, rituximab $2 \times 1000 \mathrm{mg}(\mathrm{n}=155)$

ACR, American College of Rheumatology; DAS28, Disease Activity Score (28 joints); ESR, erythrocyte sedimentation rate; EULAR, European League Against Rheumatism; FACIT-F,

Functional Assessment of Chronic Illness Therapy-Fatigue; HAQ-DI, Health Assessment Questionnaire Disability Index; LDA, low disease activity; LOCF, last observation carried forward;

MCID, minimum clinically important difference; NA, not available; SF-36, Medical Outcomes Study 36-item Short Form Health Survey. 
that occurred on day 1 of the first course of treatment (dyspnoea, laryngeal/throat irritation, nausea, pruritus, rash, throat itching and urticaria).

Over the initial 24-week period the rates of infection (all infections and serious infections) were lower in the rituximab + MTX arms compared with the placebo + MTX group (table 4). The overall rate of serious infections was 1.26 and 2.46 events

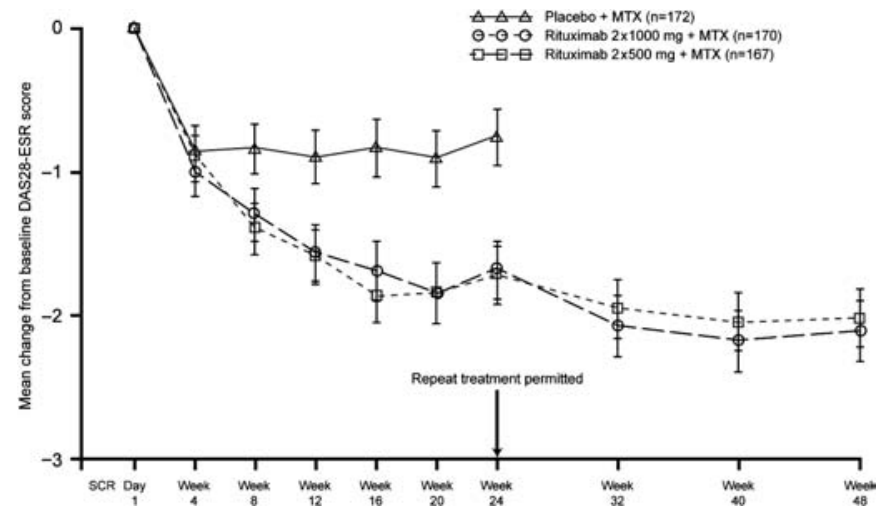

Figure 2 Mean change from baseline in Disease Activity Score (28 joints) erythrocyte sedimentation rate (DAS28-ESR) over time through to week 48, last observation carried forward imputation (intention-to-treat population). MTX, methotrexate. per 100 patient-years for rituximab $2 \times 500 \mathrm{mg}$ and $2 \times 1000 \mathrm{mg}$, respectively, compared with 8.83 events per 100 patient-years for placebo (table 4).

Four malignancies were reported during the 24-week placebo-controlled period: one each in the placebo + MTX and rituximab $(2 \times 500 \mathrm{mg})+$ MTX groups (lung adenocarcinoma and squamous cell carcinoma of the cervix, respectively) and two in the rituximab $(2 \times 1000 \mathrm{mg})+$ MTX group (oesophageal adenocarcinoma and pancreatic carcinoma (fatal)) (table 4).

The incidence of other AEs including lower gastrointestinal events, cardiac events and vascular events was similar in the rituximab groups and placebo arm (table 4).

Safety to week 48 (including second course of rituximab)

Up to week 48, the overall safety profile remained similar in the two rituximab groups (table 4).

The incidence of IRRs in those patients who received a second course of rituximab was lower than that reported for the initial course, with $10 \%$ to $11 \%$ of patients experiencing an IRR irrespective of rituximab dose. As with the initial course there were no serious IRRs, although two patients receiving rituximab $(2 \times 1000 \mathrm{mg})+$ MTX withdrew due to IRRs that occurred during their second course. One patient reported mild symptoms of headache, nausea and lethargy, whereas the second patient reported severe pruritus and rash and mild throat itching and diaphoresis.

The rates of infection, including serious infections, remained consistent with the rates observed over the initial 24 weeks

Table 4 Overall safety of placebo and rituximab $2 \times 500 \mathrm{mg}$ and $2 \times 1000 \mathrm{mg}$ (all with a stable dose of methotrexate (MTX) 10-25 mg/week) over 48 weeks (safety population)

\begin{tabular}{|c|c|c|c|c|c|}
\hline & \multicolumn{3}{|l|}{ Baseline to week 24} & \multicolumn{2}{|l|}{ Baseline to week 48} \\
\hline & $\begin{array}{l}\text { Placebo + } \\
\text { MTX ( }=172)\end{array}$ & $\begin{array}{l}\text { Rituximab } 2 \times 500 \mathrm{mg}+ \\
\text { MTX }(\mathrm{n}=167)\end{array}$ & $\begin{array}{l}\text { Rituximab } 2 \times 1000 \mathrm{mg}+ \\
\text { MTX }(\mathrm{n}=170)\end{array}$ & $\begin{array}{l}\text { Rituximab } 2 \times 500 \mathrm{mg}+ \\
\text { MTX }(\mathrm{n}=167)\end{array}$ & $\begin{array}{l}\text { Rituximab } 2 \times 1000 \mathrm{mg}+ \\
\text { MTX }(\mathrm{n}=170)\end{array}$ \\
\hline Treated (n) & 172 & 167 & 170 & 152 & 154 \\
\hline \multicolumn{6}{|l|}{ Patients with AEs, n (\%) } \\
\hline Any $\mathrm{AE}$ & $128(74)$ & $128(77)$ & $130(76)$ & $143(86)$ & $138(81)$ \\
\hline Deaths & 0 & 0 & 0 & $2(1)$ & 0 \\
\hline $\begin{array}{l}\text { AE leading to withdrawal (excluding } \\
\text { RA flare) }\end{array}$ & $2(1)$ & $2(1)$ & $3(2)$ & $3(2)$ & $7(4)$ \\
\hline \multicolumn{6}{|l|}{$\operatorname{IRR}($ any)* } \\
\hline Day 1 infusion & $24(14)$ & $31(19)$ & $42(25)$ & $19(13) \dagger$ & $17(11) \dagger$ \\
\hline Day 15 infusion & $14(8)$ & $12(7)$ & $10(6)$ & $6(4) \dagger$ & $8(5) \dagger$ \\
\hline IRR leading to withdrawal & $0(0)$ & $0(0)$ & $1(1)$ & $0(0)$ & $2(1)$ \\
\hline \multicolumn{6}{|l|}{ Infection } \\
\hline Any & $20(12)$ & $16(10)$ & $16(9)$ & $21(13)$ & $24(14)$ \\
\hline Serious & $3(2)$ & $1(1)$ & $1(<1)$ & $2(1)$ & $1(<1)$ \\
\hline \multicolumn{6}{|l|}{ Cardiac disorder events } \\
\hline Any & $4(2)$ & $5(3)$ & $7(4)$ & $8(5)$ & $8(5)$ \\
\hline Serious & $2(1)$ & $2(1)$ & $1(<1)$ & $2(1)$ & $1(<1)$ \\
\hline \multicolumn{6}{|l|}{ Vascular disorder events } \\
\hline Any & $4(2)$ & $6(4)$ & $7(4)$ & $11(7)$ & $8(5)$ \\
\hline Serious & 0 & 0 & 0 & 0 & 0 \\
\hline Malignancy & $1(<1)$ & $1(<1)$ & $2(1)$ & $1(<1)$ & $2(1)$ \\
\hline \multicolumn{6}{|l|}{$\mathrm{AE}$ rates per 100 patient-years $(95 \% \mathrm{Cl})$} \\
\hline Overall infection rate & $159.00(133.53$ to 189.34$)$ & $138.13(114.59$ to 166.52$)$ & 120.45 (98.81 to 146.82$)$ & 133.83 (116.67 to 153.52$)$ & 106.94 (91.76 to 124.63$)$ \\
\hline Serious infection $\ddagger$ rate & 8.83 (4.21 to 18.53$)$ & $1.26(0.18$ to 8.92$)$ & $2.46(0.61$ to 9.83$)$ & $2.62(0.98$ to 6.99$)$ & $1.96(0.63$ to 6.07$)$ \\
\hline
\end{tabular}

${ }^{*} \mathrm{AEs}$ occurring during or within $24 \mathrm{~h}$ of an infusion and considered by the investigator to have at least a possible relation to treatment.

tWeek 24 to week 48, based on number of patients receiving the infusion/day.

$\ddagger$ Reported as serious and/or treated with intravenous antibiotics.

$A E$, adverse event; IRR, infusion-related reaction; $R A$, rheumatoid arthritis; $S A E$, serious adverse event. 
with 2.62 and 1.96 serious infections per 100 patient-years observed for rituximab $2 \times 500 \mathrm{mg}$ and $2 \times 1000 \mathrm{mg}$ doses, respectively.

Two deaths (interstitial lung disease and abdominal sepsis) occurred between weeks 24 and 48 in patients who had received rituximab $2 \times 500 \mathrm{mg}+$ MTX; the former death was preceded by a serious infection. In addition three deaths occurred (ventricular asystole, cardiac failure and pancreatic carcinoma), one in each treatment arm, in patients who had withdrawn due to serious events prior to week 24 and subsequently died within the 48-week period.

\section{DISCUSSION}

The results of this study demonstrate that treatment with rituximab is associated with significant improvements in clinical outcomes in patients with RA with an inadequate response to MTX and who have not been previously treated with biological DMARDs. Significantly higher proportions of patients achieved the primary end point (ACR20) and this was supported by significant improvements in the majority of secondary measures including change in DAS28-ESR, EULAR and ACR50 responses, DAS28-ESR LDA and remission. There were also statistically significant and clinically important improvements in physical function, as indicated by the HAQ-DI end points, and in FACIT-F and SF-36. These data are consistent with previously reported studies showing clinical improvement with rituximab in patients with an inadequate response to DMARDs or TNF inhibitors. ${ }^{1-3}$

In contrast to previous studies, ${ }^{1-3}$ this study was conducted over a longer observation period (48 weeks vs 24 weeks) and included a second course of rituximab. Using a repeat treatment criterion based on targeting DAS28-ESR remission, the majority of patients $(90 \%)$ received a second course between weeks 24 and 48, with the majority of these given at 24-30 weeks. In rituximab-treated patients, efficacy outcomes at week 48 were comparable to those at week 24; additionally, improvement was observed for several clinically important end points, including an approximate doubling in the proportion of patients achieving LDA in the rituximab $(2 \times 1000 \mathrm{mg})+$ MTX dose group from week 24 to week 48 (table 3 ).

The current study continued to explore the effect of two dosing regimens of rituximab, $2 \times 500 \mathrm{mg}$ and $2 \times 1000 \mathrm{mg}$. Although a previous study, ${ }^{9}$ suggested higher levels of efficacy (ACR70, EULAR good response and DAS28-ESR LDA) in patients receiving rituximab $2 \times 1000 \mathrm{mg}$, the results of the current study do not appear to suggest any clinical difference between the doses, either at 24 or 48 weeks. Recent data in patients with early RA have also shown similar clinical responses for both rituximab doses; however, only the $2 \times 1000 \mathrm{mg}$ dose significantly slowed progression of joint damage. ${ }^{10}$ Therefore, despite similar clinical outcomes, the absolute requirement to also prevent joint damage would suggest that rituximab $2 \times 1000 \mathrm{mg}$ is the optimal therapeutic dose.

A consistent treatment effect for both rituximab groups compared with placebo was observed at week 24 across several clinically relevant subgroups, including baseline autoantibody status. This finding is in contrast to the more pronounced effect in patients who were RF/anti-CCP seropositive observed in a previous study. ${ }^{11}$ However, the superior response of patients who were seropositive strengthened over time, as shown by greater decreases in disease activity and enhanced ACR responses at week 48 in rituximab-treated patients who were seropositive compared with patients who were seronegative.
The safety profile observed in this study is also consistent with that of previous short-term and long-term observations of rituximab in patients with RA. ${ }^{2} 312$ As previously reported, IRRs are a primary safety concern, with the incidence highest during the first infusion of the first course. This was most evident in patients treated with rituximab $(2 \times 1000 \mathrm{mg})+$ MTX; however, the second infusion of the first course and both infusions of the second course had IRR rates that were lower than the IRR rate of the initial infusion and were comparable between rituximab doses. Irrespective of course or rituximab dose, there were no serious IRRs reported; however, three patients receiving rituximab $(2 \times 1000 \mathrm{mg})+$ MTX discontinued treatment due to IRRs.

Infections, particularly serious infections, remain a concern with all biological treatments for RA. Encouragingly, the rate of infection observed in patients receiving rituximab + MTX was low and comparable to patients receiving MTX alone over the placebo-controlled 24 -week period. This low rate of serious infection continued throughout the full 48-week period, with no obvious difference between the rituximab doses.

Although reductions in Ig levels (predominantly IgM) were observed, mean Ig levels stayed within normal limits, and there did not appear to be any association between reduced Ig concentrations and infection.

The incidence of other events of interest, including malignancies and cardiac, vascular or lower gastrointestinal events did not indicate higher rates of such events with rituximab + MTX compared with MTX alone.

Both doses of rituximab were associated with rapid and complete depletion of peripheral CD19+ B cells, with depletion and repletion patterns as previously observed. ${ }^{3}$ The incidence of immunogenicity (HACAs) was also comparable with previous results with no evidence that HACA formation altered the therapeutic or safety profile of rituximab. ${ }^{12}$

In conclusion, the results of this study confirm that rituximab is an effective and well tolerated preferred biological treatment for patients with active RA and an inadequate response to MTX.

Acknowledgements The authors wish to thank the principal investigators of the SERENE Trial Group: Ingemar Petersson, Oskarström, Sweden; Karl Grindulis, West Bromwich, UK; Tom Sheeran, Cannock, UK; Rhian Goodfellow, Cardiff, UK; Horatiu Bolosiu, Cluj-Napoca, Romania; Catalin Codreanu, Bucharest, Romania; Matija Tomsic, Ljubljana, Slovenia; Ulrich Von Hinueber, Hildesheim, Germany; Jorg Wendler, Erlangen, Germany; Andre Kahan, Paris, France; Andreas Krause, Berlin, Germany; Jorge Morales, Leon, Spain; Ruxandra Lonescu, Bucuresti, Romania; Mihai Bojinca, Bucharest, Romania; Guillermo Huerta, Aguascalientes, Mexico; Eduardo Samayoa, Guatemala City, Guatemala; Alfred Cividino, Hamilton, Ontario, Canada; WP Olszynski, Saskatoon, Saskatchewan, Canada; Rafat Faraawi, Kitchener, Ontario, Canada; Per Eriksson, Linkoeping, Sweden; Eva Baecklund, Uppsala, Sweden; Jacob Aelion, Jackson, Tennessee, USA; Adam S Barron, West Palm Beach, Florida, USA; Marcy Bolster, Charleston, South Carolina, USA; David A Bong, Vancouver, British Columbia, Canada; Richard Brasington, St Louis, Missouri, USA; Michael S Brooks, Cedar Rapids, lowa, USA; Jeffrey Butler, Spokane, Washington, USA; Andrew Chubick, Dallas, Texas, USA; John Condemi, Rochester, New York, USA Ellen Zanetakis, Tulsa, Oklahoma, USA; James Dreyfus, Munster, Indiana, USA; Larry Willis, Oklahoma City, Oklahoma, USA; Robert Ettlinger, Tacoma, Washington, USA; Jeffrey Kaine, Sarasota, Florida, USA; Michael Fairfax, Phoenix, Arizona, USA; Guy Fiocco, Lacrosse, Wisconsin, USA; Daniel Fohman, Bend, Oregon, USA; Reynold Karr, Everett, Washington, USA; Joseph Z Forstot, Boca Raton, Florida, USA; Norman Gaylis, Aventura, Florida, USA; Robert Griffin, West Reading, Pennsylvania, USA; Jeffrey Lawson, Simpsonville, South Carolina, USA; George Liang, Chicago, Illinois, USA; John Looney, Rochester, New York, USA; Cummins Lue, Little Rock, Arkansas, USA; William Palmer, Omaha, Nebraska, USA; Charles Pritchard, Willow Grove, Pennsylvania, USA; Luggen, Cincinnati, Ohio, USA; David Mandel, Mayfield, Ohio, USA; Benard Rubin, Fort Worth, Texas, USA; Constantine K Saadeh, Amarillo, Texas, USA; Michael Sayers, Colorado Springs, Colorado, USA; Joy Schechtman, Peoria, Arizona, USA; Evan Siegal, Wheaton, Maryland, USA; Michael Snack, Indianapolis, Indiana, USA; Jeffrey Neal, Lexington, Kentucky, USA; Ewa Olech, Oklahoma City, Oklahoma, USA; Nadera Sweiss, Chicago, Illinois, USA; Saima Chohan, Chicago, 
Illinois, USA; Christopher G Jackson, Salt Lake City, Utah, USA; Richard Jimenez, Seattle, Washington, USA; Lawrence Brent, Philadelphia, Pennsylvania, USA; Steven Ecklund, Meridian, Idaho, USA; Pamela Freeman, Orlando, Florida, USA; David Sises, Zephyrhills, Florida, USA; Christopher Striebich, Aurora, Colorado, USA; David Holt, Spartanburg, South Carolina, USA; Steven J Klein, Cumberland, Maryland, USA; Jefrey Lieberman, Decatur, Georgia, USA; Geoffrey Gladstein, Bridgeport, Connecticut, USA; Daksha P Mehta, Elizabethtown, Kentucky, USA; Mario Humberto Cardiel Rios, Morelia, Mexico; Steven Stern, Louisville, Kentucky, USA; A Gough, Harrogate, UK; Robert Trapo, Springfield, Illinois, USA; Morges Sisay, Evansville, Indiana, USA; Asad Fraser, Bowling Green, Kentucky, USA; Anthony Saway, Birmingham, Alabama, USA; Cesar Pacheco, Chihuahua, Mexico; Mike Green, Cork, Ireland; Deborah Desir, Hamden, Connecticut, USA; Marcin Gornisiewicz, Knoxville, Tennessee, USA; Edmund Edelmann, Bad Aibling, Germany; R Franklin, Memphis, Tennessee, USA; Charles Birbara, Worcester, Massachusetts, USA; Philip Taylor, Cape Girardeau, Missouri, USA; Alastair Kennedy, Vero Beach, Florida, USA; Michael Miniter, Moline, Illinois, USA; Allen Samuels, Bethlehem, Pennsylvania, USA. The authors are also grateful to Tim Shaw, Mark Reynard, Fiona Langley and Buki Akinola (Roche Products Ltd), and Lachy McLean, Min Bao, Benjamin Trzaskoma and Jennifer Rubin (Genentech). This manuscript was prepared by Matthew Pugh (Adelphi Communication Ltd) in consultation with Roche, Genentech and the authors.

Funding This study was sponsored by Hoffmann-La Roche, Genentech and Biogen Idec.

Competing interests $\mathrm{PE}$ has received research grants and consulting fees from Roche and research grants from Abbott. AD has received payments for educational lectures, teleconferences and serving on advisory boards for Genentech, a company that may have a commercial interest in the results of this research. This potential conflict of interest has been reviewed and managed by OHSU. WFR has received speaker fees from Genentech, Abbott, Biogen Idec and Bristol-Myers Squibb; clinical trial payments from Genentech, Abbott, Roche and Bristol-Myers Squibb; and consulting fees from Genentech, Roche, Biogen Idec and Amgen. JDI has received consulting fees from Roche and speaker fees from Roche and Biogen Idec. BC has received speaker fees and consulting fees from Abbott, Bristol-Myers Squibb, Roche, Schering-Plough, UCB and Wyeth. KL has received speaker fees from Genentech, Abbott, Centocor and Bristol-Myers Squibb; clinical trial payments from Genentech, Centocor, Bristol-Myers Squibb and Amgen; and consulting fees from Genentech. $\mathrm{AC}$ is an employee of Genentech, a member of the Roche Group; GKA, WD and HT are employees of Roche. AJR, CA-M, LJS and RAR have no competing interests to declare.

Ethics approval Approval from the Independent Ethics Committee (IEC) was obtained before starting the study.

Provenance and peer review Not commissioned; not externally peer reviewed.

\section{REFERENCES}

1. Edwards JC, Szczepanski L, Szechinski J, et al. Efficacy of B-cell-targeted therapy with rituximab in patients with rheumatoid arthritis. N Engl J Med 2004;350:2572-81.

2. Cohen SB, Emery P, Greenwald MW, et al. Rituximab for rheumatoid arthritis refractory to anti-tumor necrosis factor therapy: results of a multicenter, randomized, double-blind, placebo-controlled, phase III trial evaluating primary efficacy and safety at twenty-four weeks. Arthritis Rheum 2006;54:2793-806.

3. Emery P, Fleischmann R, Filipowicz-Sosnowska A, et al. The efficacy and safety of rituximab in patients with active rheumatoid arthritis despite methotrexate treatment: results of a phase IIB randomized, double-blind, placebo-controlled, dose-ranging trial. Arthritis Rheum 2006;54:1390-400.

4. Felson DT, Anderson JJ, Boers M, et al. The American College of Rheumatology preliminary core set of disease activity measures for rheumatoid arthritis clinical trials. The Committee on Outcome Measures in Rheumatoid Arthritis Clinical Trials. Arthritis Rheum 1993;36:729-40.

5. Wells GA, Tugwell P, Kraag GR, et al. Minimum important difference between patients with rheumatoid arthritis: the patient's perspective. J Rheumatol 1993;20:557-60.

6. Lubeck DP. Patient-reported outcomes and their role in the assessment of rheumatoid arthritis. Pharmacoeconomics 2004;22(Suppl 1):27-38.

7. Norman GR, Sloan JA, Wyrwich KW. Interpretation of changes in health-related quality of life: the remarkable universality of half a standard deviation. Med Care 2003:41:582-92.

8. Cella D, Yount S, Sorensen M, et al. Validation of the Functional Assessment of Chronic IIIness Therapy Fatigue Scale relative to other instrumentation in patients with rheumatoid arthritis. J Rheumato/ 2005;32:811-19.

9. Mease PJ, Revicki DA, Szechinski J, et al. Improved health-related quality of life for patients with active rheumatoid arthritis receiving rituximab: results of the DoseRanging Assessment: International Clinical Evaluation of Rituximab in Rheumatoid Arthritis (DANCER) Trial. J Rheumato/ 2008;35:20-30.

10. Tak PP, Rigby WFC, Rubbert-Roth A, et al. Rituximab in combination with methotrexate (MTX) significantly inhibits joint damage and improves clinical outcomes in patients with early active RA who are naïve to MTX: a randomized, active comparator placebo-controlled trial (IMAGE). Arthritis Rheum 2009;60(Suppl 10):S238, Abstract 636

11. Tak PP, Cohen SB, Emery P, et al. Clinical response following the first treatment course with rituximab: effect of baseline autoantibody status (RF, anti-CCP). Ann Rheum Dis 2007;66(Suppl II):338.

12. Keystone $\mathbf{E}$, Fleischmann R, Emery P, et al. Safety and efficacy of additional courses of rituximab in patients with active rheumatoid arthritis: an open-label extension analysis. Arthritis Rheum 2007;56:3896-908. 